\title{
Study the Effect of Annealing Temperature and Thickness on the Structural, Optical Properties of the $(\mathrm{CdTe})$ Thin Films
}

\author{
D. Ramiz Ahmed Mohamed ${ }^{1}$, Dr. Fallah Ibrahim Mustafa ${ }^{2}$, Dhuha Kareem Harfash ${ }^{3}$ \\ ${ }^{1,3}$ University of Baghdad, Department of Physics, College of Science for Women \\ ${ }^{2}$ Solar Research Center, Ministry of Science and Technology, Baghdad, Iraq
}

\begin{abstract}
Thin films of CdTe were prepared in the thickness (500 and $1000 \mathrm{~nm}$ ) on the glass substrate by vacuum evaporation technique at room temperature then put in different annealing temperatures $(300,373,473,573) \mathrm{K}$ for one hour. From the study Structural properties of the thin films by the $X$ - ray diffraction, we found polycrystalline nature and with a preferred orientation along [111] cubic and increasing density when increasing the annealing temperature and found the new peaks at the annealing temperature of (573) $\mathrm{K}$ for $\mathrm{CdO}$. The Transmittance spectrum was recorded as a function of wavelength range (500-1100) nm. The energy gap increase when the increase thickness and annealing temperature.
\end{abstract}

Keywords: thin films, CdTe, thermal evaporation technique, $\mathrm{X}$ - ray diffraction

\section{Introduction}

II-VI semiconductors compound of considerable interest because of their extensive use in the fabrication of photovoltaic devices cells [1,2]. Cadmium telluride (CdTe) is one of the most promising polycrystalline materials for thin film solar cells due to its physical properties: It has a direct band gap (approximately $1.5 \mathrm{eV}$ ) with a high absorption coefficient (larger than $10^{5} \mathrm{~cm}^{-1}$ at wavelengths around $700 \mathrm{~nm}$ ), so that only thin film layers (a few microns) are needed for the absorption of the most of the solar spectra photons with energy higher than the band gap, and it can be obtained as p-type. Some of the commonly used low cost growth techniques for CdTe thin film production include electrodeposition, spray pyrolysis and close-spaced sublimation [3].CdTe is a strong competitor to solar cells and low cost because it has a direct energy gap, Up to $1.53 \mathrm{eV}$ at RT, and Absorption coefficient $\left(\alpha>10^{4} \mathrm{~cm}\right.$ $\left.{ }^{1}\right)$ at The visible spectrum, CdTe thin films can be deposited with more than one technique, including vacuum evaporation, hot-luminous fumigation, molecular deposition, electrolysis [4].

\section{Experimental Work}

In this research, we have arranged a thin layer of cadmium spectra on glass bases at R.T., and studied the effect of annealing temperature and change of thicknees on structural and optical properties by finding absorption coefficients and optical constants, such as energy gap and refractive index. In this study, We use a standard CdTe alloy, of purity (99.999) $\%$ on corning glass substrate, cleaned by methanol and washing in ultrasonic vibrator with deionized water, were prepared by thermal evaporation technique (Edward Coating system E306A) under a vacuum of pressure of the order $\left(3 * 10^{-5}\right)$ mbar.

X-ray diffraction technique was used to investigate the heterojunction structures. The experiments were carried out usingthe (Philips PW 1840) $(\mathrm{Cu}-\mathrm{K} \alpha)$ radiation of average wavelength $1.54056 \AA$. The diffraction pattern was recorded between $2 \theta=\left(10^{\circ}-60^{\circ}\right)$. By comparing the interpleader distance for different planes (dhk) value with ASTM card for CdTe have been examined the structure. The grain size (D) was calculated using XRD analysis from Scherer relation [5]

$$
D=0.9 \lambda / \beta \cos \theta
$$

Where $\lambda$ is $X$-ray wavelength, $\beta$ is the full width at half maximum intensity (full width at half maximum intensity (FWHM)) and $\theta$ is the diffraction angle (Bragg angle). The grain size was calculated using FWHM of (111) plane.

The optical properties that include the (T) Transmittance of the annealing temperature $(373,473,573) \mathrm{K}$ were measured for one hour. Using UV-Vis-Spectrophotometer type (UV2610) within the range of wavelength (200-1100) nm, calculation energy gap and refractive index.Werecalculated the value of the electrical connection was measured using a (Keithly 2182A) nanovoltmeter device.

\section{Results and Discussion}

From Figure (1), which represents XRD results for the pure CdTe films of the temperature K (300), it has three peaks in the direction [111] [202] [311], which means that the pure films have a polycrystalline (Cubic) and the dominant trend [111]. shows the effect of annealing temperature in the thin films. The results of X-ray diffraction showed a marked change in the intensity of the diffraction peaks after the thickness and the temperature of the $\mathrm{k}(373,473.573)$ respectively. The thickness of the nm $(500)(373,573)$ was indicative of crystalline growth and the appearance of other peaks compared to standard ASTM (96-900-8841) for CdTe. was observed at the annealing temperature (573) KAppearance of peak of $\mathrm{CdO}$ at the direction (200) due to the occurrence of oxidation rate in the films due to working conditions can be seen as in Figure (2),As for thicknees (1000) $\mathrm{nm}$ for the annealing temperature (573) $\mathrm{K}$ In the crystalline direction (020) as well as the appearance of the

\section{Volume 6 Issue 12, December 2017}




\section{International Journal of Science and Research (IJSR) \\ ISSN (Online): 2319-7064}

Index Copernicus Value (2016): 79.57 | Impact Factor (2015): 6.391

material $\mathrm{CdO}$ shows that an increase in the thickness and annealing temperature has an effect on the increased crystallization of thin films, This indicates that the process of annealinghelps improve the crystallization process. can be seen as in Figure (3). The results showed an increase in grain size at the annealing temperature of $(373,473,573) \mathrm{K}$ and $(1000,500)(\mathrm{nm})$ in the preferred direction $(111)$, Due to the increased crystallization and decrease of crystalline defects, tables (1) to (2) show the obtained results.

Calculated Transmittance $(\mathrm{T})$ and the relation between the Transmittance and the wavelength $(\lambda)$ were plotted with the change of both the thickness and the annealingtemperature. Seen as in Figure (4)and (5). The increase in Transmittance with increasing wavelength for all thinfilms.

Calculated The optical energy gap of the CdTe films with the change of the thicknees before and after the annealing by drawing the relation $(\alpha h v)^{2}$ as the function of the photon energy according calculated from the equation (2)[6]Seen as in Figure (6) and(7)

$$
\alpha h v=B\left(h v-\mathbf{E g}^{\text {opt }}\right)^{\mathbf{r}}
$$

The absorption results show that the prepared films have a high absorbance factor of $\left(\alpha>10^{4} \mathrm{~cm}^{-1}\right)$, This resulted in the elimination of the defects in the energy gap after the growth and rearrangement of the crystalline grains, which confirmed the results of X-ray diffraction, and this is consistent with the results of the sources $[7,8,9]$.

The table (3) shows that the energy gap values are increased by $(1.48-1.84) \mathrm{eV},(1.42-1.73) \mathrm{eV}$, with both the $(373,473,573) \mathrm{K}$ and the thickness of $1000,500(\mathrm{~nm})$.

The refractive index, defined as the ratio between the velocity of light in the vacuum and its velocity within the material, was calculated using equation (3)[10]

$$
n=\left(\frac{4 R}{(R-1)^{2}}-k^{2}\right)^{1 / 2}-\frac{(R+1)}{(R-1)}
$$

decrease by increasing the wavelength, improvement in the crystal structure and an increase in the density of compaction.

\section{Conclusions}

1) The results of $X$-ray tests showed that all thin films prepared by vacuum evaporation in the vacuum have a poly-crystalline structure.

2) 2.The results showed an increase in grain size at theincreases annealing temperature and thickness.

3) CdTe thickness has a high absorption factor in the visible area of the electromagnetic spectrum, which means that they can be used to manufacture solar cells and a direct energy gap.

4) Thinfilms have high Transmittance in the infrared region, which means that these thin films can be used as a window in this region of the electromagnetic spectrum.

5) 5.The results showed an increase in energy gap at theincreases annealing temperature

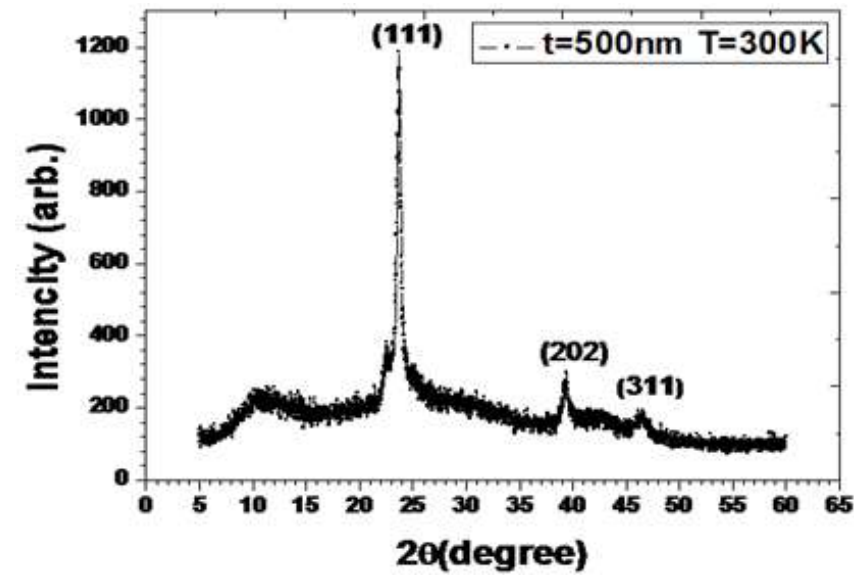

Figure 1: Shows the $\mathrm{X}$-ray diffraction at $500 \mathrm{~nm}$ thickness for temperatures (300) $\mathrm{K}$

Figure (8) $(\mathrm{a}, \mathrm{b})$ shows that the refractive index is changed as a wavelength function with each temperature change And the shapes show that the values of the refractive index

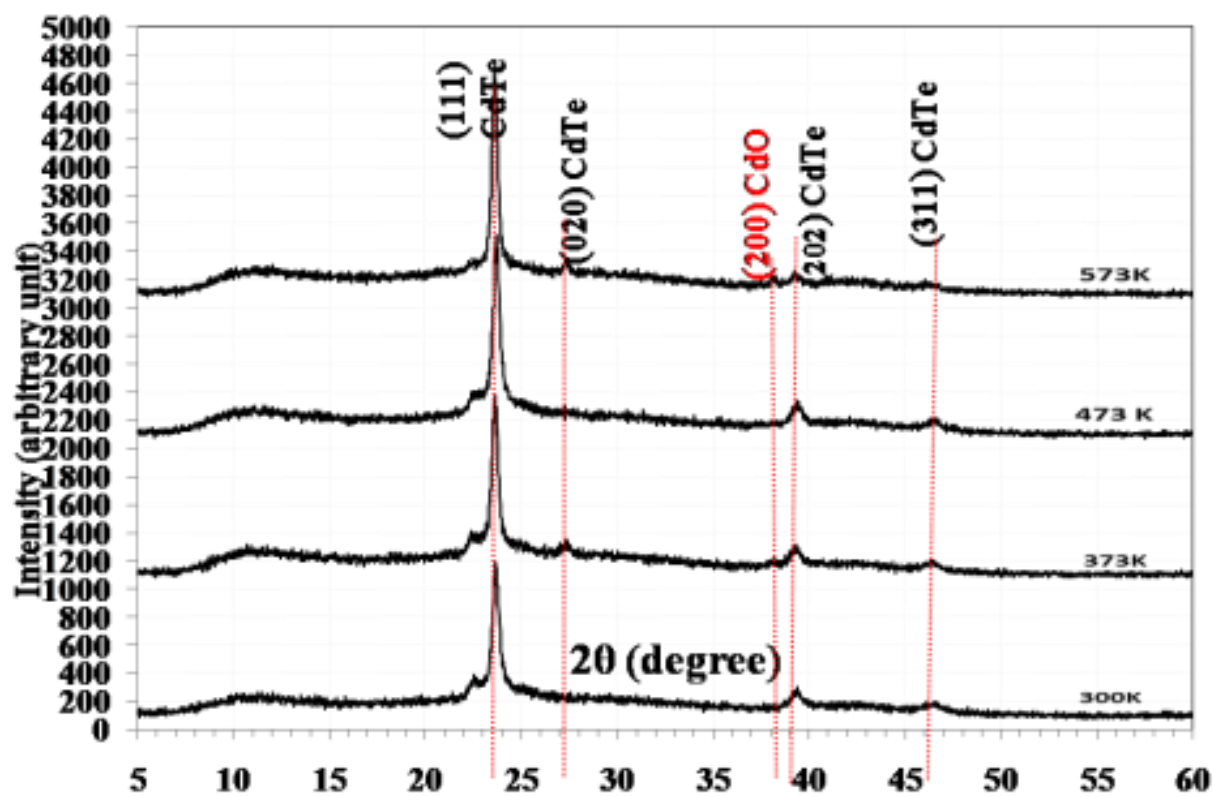

Figure 2: shows the X-ray diffraction for thin films (CdTe) at $500 \mathrm{~nm}$ thickness for temperatures (a) $300 \mathrm{~K}$, (b) $373 \mathrm{~K}$, (c), $473 \mathrm{~K}(\mathrm{~d}) 573 \mathrm{~K}$

Volume 6 Issue 12, December 2017 www.ijsr.net 
International Journal of Science and Research (IJSR)

ISSN (Online): 2319-7064

Index Copernicus Value (2016): 79.57 | Impact Factor (2015): 6.391

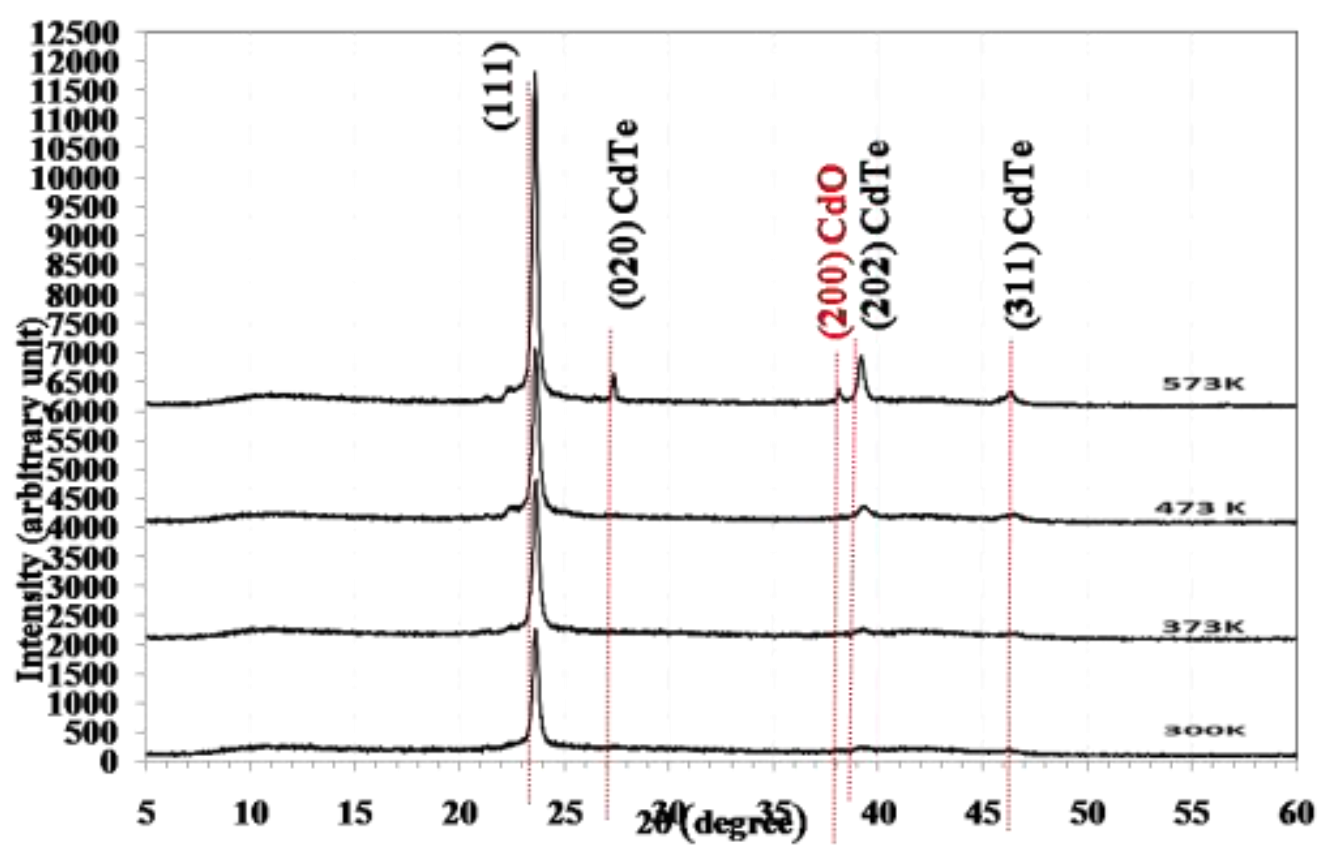

Figure 3: shows the $\mathrm{X}$-ray diffraction thin films for(CdTe) $1000 \mathrm{~nm}$ thickness for temperatures (a) $300 \mathrm{~K}$, (b) $373 \mathrm{~K}$, (c), $473 \mathrm{~K}$ (d) $573 \mathrm{~K}$

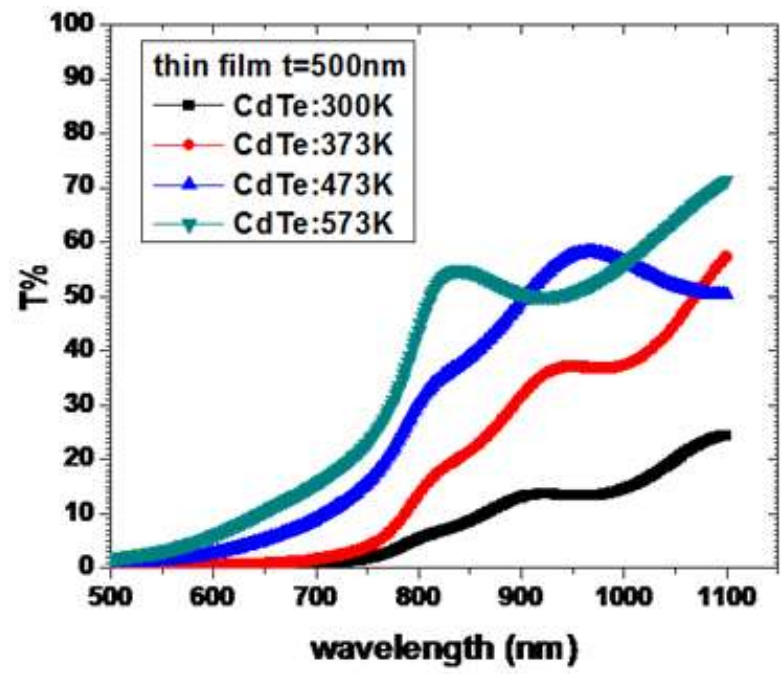

Figure 4: Change the Transmittance spectrum with the wavelength of the films (CdTe) for a function of the

annealing temperature at thicknees $500 \mathrm{~nm}$

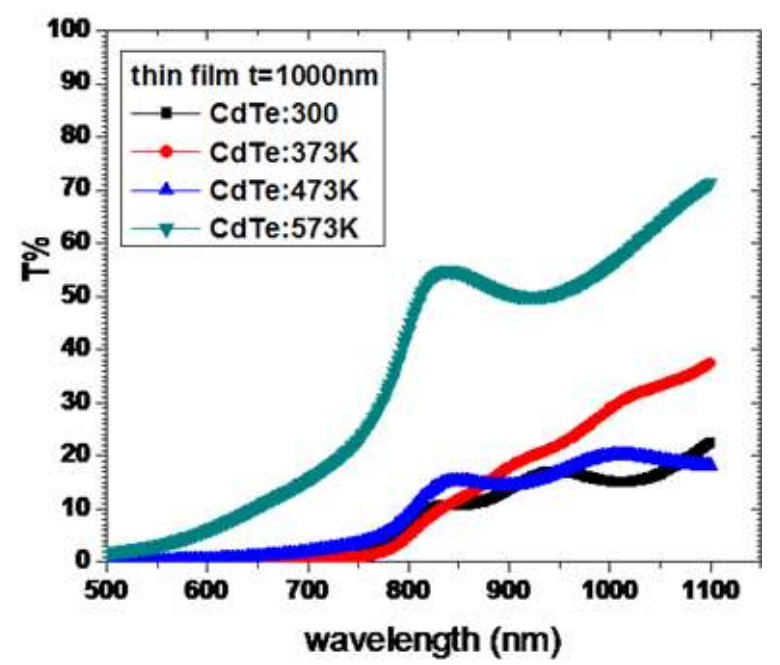

Figure 5: Change the Transmittance spectrum with the wavelength of the thin films (CdTe) for a function of the annealing temperature at thicknees $1000 \mathrm{~nm}$

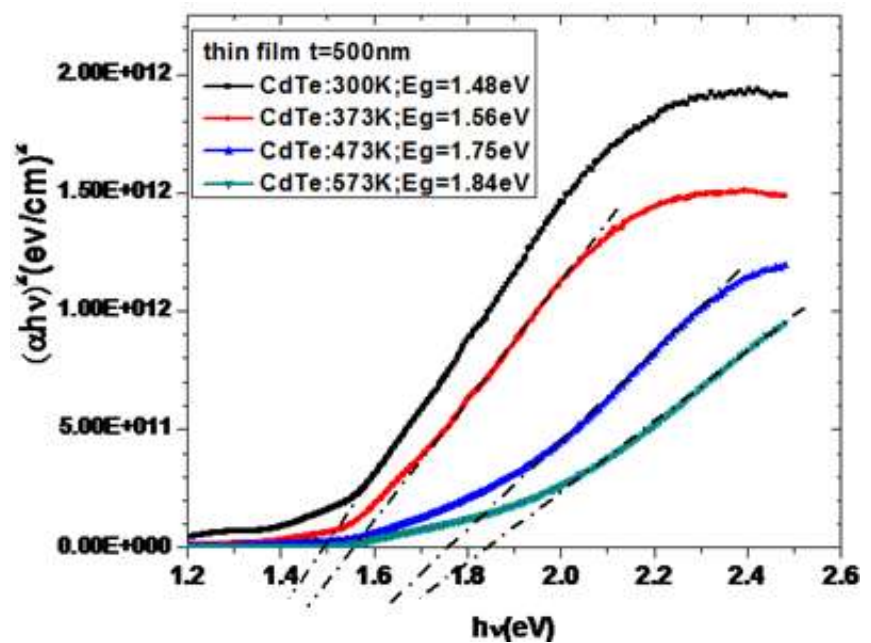

Figure 6: Change the values of the optical energy gap as a function of photon energy at $500 \mathrm{~nm}$

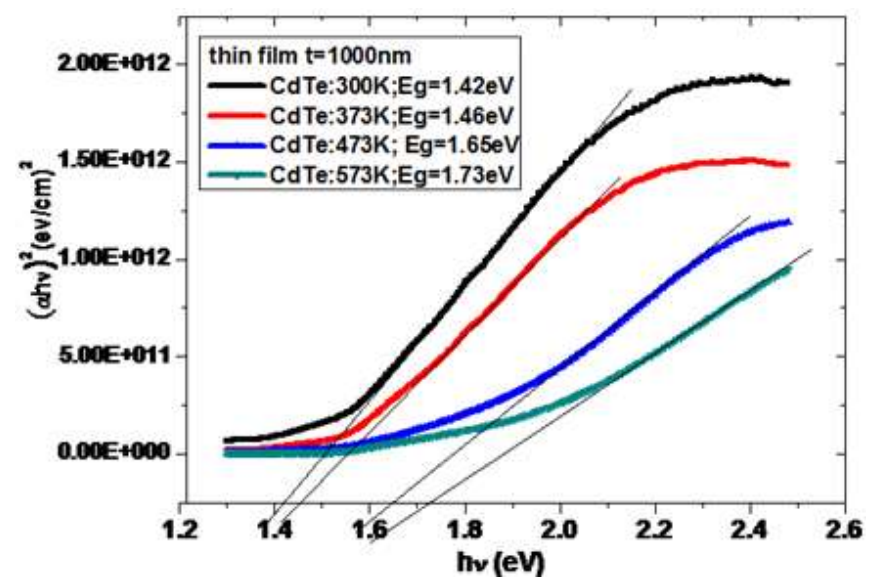

Figure 7: Change the values of the optical energy gap as a function of photon energy at $1000 \mathrm{~nm}$

Volume 6 Issue 12, December 2017 www.ijsr.net 


\title{
International Journal of Science and Research (IJSR) \\ ISSN (Online): 2319-7064
}

Index Copernicus Value (2016): 79.57 | Impact Factor (2015): 6.391
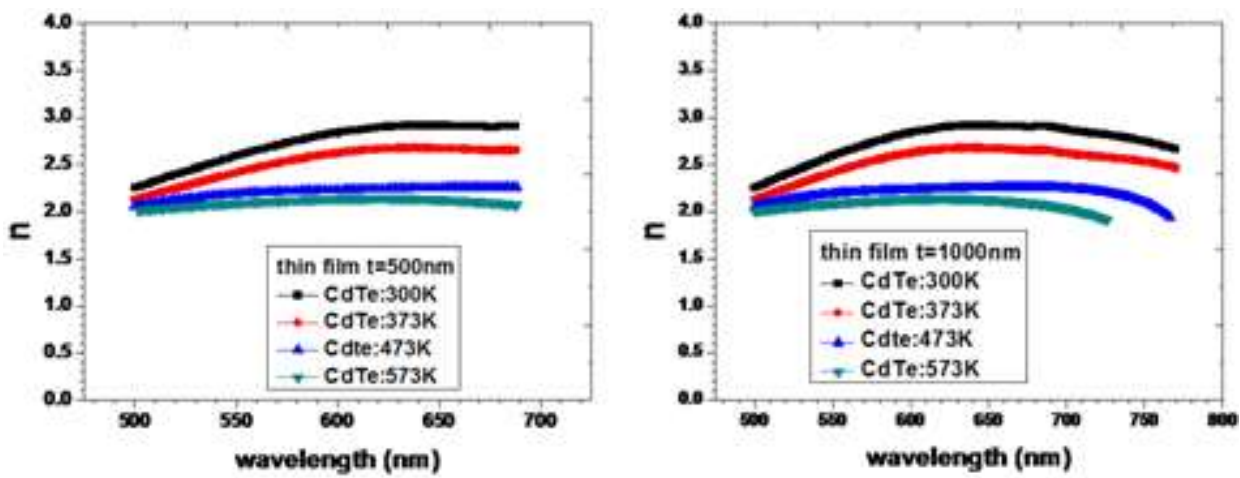

Figure 8: Change refractive index values with wavelength as a function of theannealing temperature at thicknees (a) 500nm,

(b) $1000 \mathrm{~nm}$

Table 1: values of d, FWHM, G.SWith changes temperature for CdTe thin films at thicknees (500) nm

\begin{tabular}{|c|c|c|c|c|c|c|c|c|}
\hline $\mathrm{T}_{\mathrm{a}(\mathrm{K})}$ & $2 \theta$ (Deg.) & $\begin{array}{l}\begin{array}{l}\text { FWHM } \\
\text { (Deg.) }\end{array} \\
\end{array}$ & $\mathrm{d}_{\mathrm{hkl}} \operatorname{Exp} .(\AA)$ & $\begin{array}{c}\text { G.S } \\
(\mathrm{nm})\end{array}$ & $\begin{array}{c}\mathrm{d}_{\mathrm{hkl}} \\
\text { Std. }(\AA) \\
\end{array}$ & Phase & hkl & card No. \\
\hline \multirow[t]{3}{*}{300} & 23.7060 & 0.4223 & 3.7502 & 19.2 & 3.7387 & $\mathrm{CdTe}$ & (111) & 96-900-8841 \\
\hline & 39.3564 & 0.7204 & 2.2875 & 11.7 & 2.2913 & $\mathrm{CdTe}$ & (202) & 96-900-8841 \\
\hline & 46.5108 & 1.0185 & 1.9510 & 8.5 & 1.9526 & CdTe & (311) & $96-900-8841$ \\
\hline \multirow{4}{*}{373} & 23.6811 & 0.3975 & 3.7541 & 20.4 & 3.7387 & $\mathrm{CdTe}$ & (111) & 96-900-8841 \\
\hline & 27.3080 & 0.4969 & 3.2632 & 16.5 & 3.2397 & CdTe & $(020)$ & 96-900-8841 \\
\hline & 39.3067 & 0.6707 & 2.2903 & 12.6 & 2.2913 & $\mathrm{CdTe}$ & (202) & $96-900-8841$ \\
\hline & 46.4363 & 0.6956 & 1.9539 & 12.4 & 1.9526 & $\mathrm{CdTe}$ & (311) & 96-900-8841 \\
\hline \multirow{3}{*}{473} & 23.7060 & 0.3726 & 3.7502 & 21.8 & 3.7387 & CdTe & (111) & 96-900-8841 \\
\hline & 39.4309 & 0.5963 & 2.2834 & 14.2 & 2.2913 & $\mathrm{CdTe}$ & (202) & 96-900-8841 \\
\hline & 46.5357 & 0.6211 & 1.9500 & 13.9 & 1.9526 & CdTe & (311) & $96-900-8841$ \\
\hline \multirow{5}{*}{573} & 23.6066 & 0.3229 & 3.7658 & 25.1 & 3.7387 & CdTe & (111) & 96-900-8841 \\
\hline & 27.3080 & 0.2981 & 3.2632 & 27.4 & 3.2397 & $\mathrm{CdTe}$ & $(020)$ & 96-900-8841 \\
\hline & 38.1391 & 0.3229 & 2.3577 & 26.0 & 2.3612 & $\mathrm{CdO}$ & (200) & 96-101-1097 \\
\hline & 39.2818 & 0.3727 & 2.2917 & 22.6 & 2.2913 & CdTe & (202) & $96-900-8841$ \\
\hline & 46.3369 & 0.6210 & 1.9579 & 13.9 & 1.9526 & $\mathrm{CdTe}$ & (311) & 96-900-8841 \\
\hline
\end{tabular}

Table 2: values of d, FWHM, G.SWith changes temperature for CdTe thin films at thicknees (1000) nm

\begin{tabular}{|c|c|c|c|c|c|c|c|c|}
\hline $\mathrm{T}_{\mathrm{a}(\mathrm{K})}$ & $2 \theta$ (Deg.) & $\begin{array}{c}\begin{array}{c}\text { FWHM } \\
\text { (Deg.) }\end{array} \\
\end{array}$ & $\mathrm{d}_{\mathrm{hkl}} \operatorname{Exp} .(\AA)$ & $\begin{array}{l}\text { G.S } \\
(\mathrm{nm})\end{array}$ & $\begin{array}{r}\mathrm{d}_{\mathrm{hkl}} \\
\text { Std. }(\AA) \\
\end{array}$ & Phase & hkl & card No. \\
\hline \multirow[t]{3}{*}{300} & 23.6360 & 0.3701 & 3.7612 & 21.9 & 3.7387 & $\mathrm{CdTe}$ & $(111)$ & $96-900-8841$ \\
\hline & 39.2575 & 0.7051 & 2.2931 & 12.0 & 2.2913 & CdTe & $(202)$ & $96-900-8841$ \\
\hline & 46.3675 & 0.9402 & 1.9567 & 9.2 & 1.9526 & $\mathrm{CdTe}$ & $(311)$ & $96-900-8841$ \\
\hline \multirow{3}{*}{373} & 23.6525 & 0.3631 & 3.7586 & 22.4 & 3.7387 & CdTe & $(111)$ & $96-900-8841$ \\
\hline & 39.3172 & 0.4457 & 2.2897 & 18.9 & 2.2913 & CdTe & $(202)$ & 96-900-8841 \\
\hline & 46.3325 & 0.5117 & 1.9581 & 16.9 & 1.9526 & CdTe & $(311)$ & $96-900-8841$ \\
\hline \multirow{3}{*}{473} & 23.6360 & 0.3136 & 3.7612 & 25.9 & 3.7387 & $\mathrm{CdTe}$ & $(111)$ & $96-900-8841$ \\
\hline & 39.3007 & 0.3797 & 2.2907 & 22.2 & 2.2913 & $\mathrm{CdTe}$ & $(202)$ & $96-900-8841$ \\
\hline & 46.5141 & 0.3797 & 1.9508 & 22.8 & 1.9526 & $\mathrm{CdTe}$ & $(311)$ & 96-900-8841 \\
\hline \multirow{5}{*}{573} & 23.6194 & 0.2806 & 3.7638 & 28.9 & 3.7387 & CdTe & $(111)$ & $96-900-8841$ \\
\hline & 27.3830 & 0.1816 & 3.2544 & 45.0 & 3.2397 & CdTe & $(020)$ & $96-900-8841$ \\
\hline & 38.1288 & 0.1816 & 2.3583 & 46.3 & 2.3612 & $\mathrm{CdO}$ & (200) & 96-101-1097 \\
\hline & 39.1852 & 0.3466 & 2.2971 & 24.3 & 2.2913 & $\mathrm{CdTe}$ & $(202)$ & $96-900-8841$ \\
\hline & 46.2830 & 0.2641 & 1.9600 & 32.7 & 1.9526 & $\mathrm{CdTe}$ & $(311)$ & $96-900-8841$ \\
\hline
\end{tabular}

Table 3: Change the values of the optical energy gap with theannealing temperature and thicknees

\begin{tabular}{|c|c|c|c|c|}
\hline \multirow{2}{*}{$\begin{array}{c}\text { Thickness } \\
(\mathrm{nm})\end{array}$} & $\mathrm{T}=300 \mathrm{~K}$ & $\mathrm{~T}=373 \mathrm{~K}$ & $\mathrm{~T}=473 \mathrm{~K}$ & $\mathrm{~T}=573 \mathrm{~K}$ \\
\cline { 2 - 5 } & $\mathrm{Eg}^{\text {opt }}(\mathrm{eV})$ & $\mathrm{Eg}^{\text {opt }}(\mathrm{eV})$ & $\mathrm{Eg}^{\text {opt }}(\mathrm{eV})$ & $\mathrm{Eg}^{\mathrm{opt}}(\mathrm{eV})$ \\
\hline 500 & 1.48 & 1.56 & 1.75 & 1.84 \\
\hline 1000 & 1.42 & 1.46 & 1.65 & 1.73 \\
\hline
\end{tabular}

\section{References}

[1] S. T. Sundari, V. Swaminthan, A. K. Tyagi and T. Mahalingam, (2000), "Phys. Stat. Sol. (a)", Vol. 177, pp. 495-502.
[2] Z.K.Heiba, (2003), "Crys. Res. Technol.", Vol. 38, pp. 488-49.

[3] E. Bacaksiz, M. Altunbaș, S. Yılmaz, M. Tomakin, and M. Parlak, (2007)," Cryst. Res. Technol", Vol. 42, No.9, pp. $890-894$

[4] Kolosov, S. A.; Klevkov, Yu. V. and Plotnikov, A. F. (2004), Semiconductors , "Electrical Properties of FineGrained Polycrystalline CdTe", 38(4) :455-460.

[5] A.M. Al Dhafiri, (2001), "Crys. Res. Techno.", Vol. 37, No. 9, pp. 950- 957

[6] S. O. Kasap, "Principles of Electronic Materials and Devices", 2nd Edition , McGraw-Hill, higher education, New York, (2002).

\section{Volume 6 Issue 12, December 2017}

\author{
www.ijsr.net
}

Licensed Under Creative Commons Attribution CC BY 


\section{International Journal of Science and Research (IJSR) \\ ISSN (Online): 2319-7064}

Index Copernicus Value (2016): 79.57 | Impact Factor (2015): 6.391

[7] E. R. Shaaban, N. Afify, and A. El-Taher, "Effect of film thickness on microstructure parameters and optical constants of CdTe thin films", Journal of Alloys and Compounds Vol. 482, pp.(400-404), (2009).

[8] G.G. RUSU, "Structural, electronic transport and optical properties of Zn-doped CdTe thin films", Journal Of Opt. And Advanced Materials Vol. 8, No. 3 , p. 931 - 935,( 2006).

[9] Mustafa Mohammed "Study the optical, electrical and structural properties of siliconbasedCdTesolarcell",College of Science, University of Baghdad,(2013).

[10]Dr.eng. A.Badawieh and Dr.eng. N.Shahin " fundamentals of electronic engineering " demshk university (2004).

Volume 6 Issue 12, December 2017

www.ijsr.net 